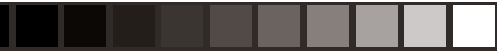 \\ Sobre cangurus, degraus e limites
}

\author{
Mauricio Paroni de Castro
}

O inverso da verdade tem dez mil formas e um campo ilimitado. Michel de Montaigne.

igo o que puder relatar desde que tomei o avião para São José do Rio Preto. São pensamentos que puderam ser verbalizados ali mesmo, uma vez serem eles bem mais velozes que a minha capacidade semântica. Certamente reproponho coisas escritas durante certas viagens teatrais que fiz anteriormente, que deixarei em itálico, para melhor informação do leitor. Para quem os conhece, isso servirá para verificar como certas convicções mudaram ou se reforçaram a cada espetáculo visto: mas a maior reflexão será a do leitor. Quem sabe não cruzaremos as opiniōes um dia?

\section{Cangurus e degraus: nada além de uma performance sobre limites do teatro}

Viver é o meu trabalho e a minha arte. Michel de Montaigne.

Por ser cadeirante, virei alvo da curiosidade dos passageiros do avião que nos levou a Rio Preto graças à singularidade de uma maquina italiana que pulava os degraus da escada comigo trepa- do em cima. Ao abrir- se a porta da aeronave, precisei de uma espécie de canguru mecânico para descer. Havia vivido experiências curiosas com geringonças estranhas usadas para cadeirantes, mas jamais com pensamentos de Montaigne na cabeça.

A cada degrau notei que participara a muitos festivais, mas somente como artista: jamais como uma pessoa paga para pensar o que quisesse. Os produtores e demais organizadores culturais em geral podem fazer, participar e assistir a festivais com relativa distancia critica. Artistas, nunca: ficam demasiadamente dentro do jogo. Saltando escada abaixo, festejava, feliz, o quanto poderia refletir e observar os limites e formas da realidade e do espetáculo sobre as criaçôes (dos outros!). Mais ainda, criaçôes de varias culturas de espetáculo diferentes.

Vivi intensamente cada degrau daquela escadinha, limitado pelo medo de uma queda do "canguru". Alguns degraus foram dedicados aos políticos e aos secretários de cultura. Professam carateres de ideias dominantes (Sejam elas "de direita" - assim chamadas pela "esquerda" - que poderiam combater o teatro dito "comercial", mas nada mais são que um mal feito artesanato do riso baixo... sejam elas "de esquerda" - assim chamadas pela "direita" - uma práxis

Mauricio Paroni de Castro é dramaturgo e encenador. Este texto é o seu relato como observador convidado do Festival Internacional de Teatro de São José do Rio Preto de 2010. 
de trabalhadores teatrais que os faz combatentes do teatro que pugnador das "transformaçôes sociais" que visam ensinar aos pobres e periféricos como deveriam lutar para viver. Todos acabam por patrocinar uma espécie de teatro mistificado com os piores vícios convencionais. Mistificação usurpadora de um teatro mais genuíno, mais ligado à nossa rica humanidade. Resquício dos tempos a ditadura e consequência dela - herdamos ingenuamente nessa briga a coroação de um projeto estadunidense dos tempos de Nixon que era destruir qualquer práxis cultural que pudesse realmente emancipar nosso pais. Ainda não temos, em nossa política, qualquer liderança ou ideia forte que nos seja útil de verdade culturalmente.

$$
\text { Mais degraus. }
$$

\section{A estética refinada e simples do New York City Players}

Uma caixa com um simples refletor de slides era empregada para iluminar o ambiente: uma verdadeira "camera oscura". O publico se funde na luz enquanto vetor de invenção cênica. Há um radical despojamento da forma e das vozes. A ausência da mascara mas não da tensão ficcional é a base gramática do espetáculo.

Lembrei-me de que havia iluminado, no Brasil, uma imensa pilha de jornais em 1988 com o Língua de Montanha, de Harold Pinter, mas sem tal eficácia com o publico. A dramaturgia contemporânea de língua inglesa, essencial, leva à essa essencialidade nas imagens da performance. Sam Shepard, Mamet, influenciaram Maxwell, como diretor e como dramaturgo. Ali, essas as funções são inseparáveis. $A$ in fluência não foi somente de texto, do heroi americano que não existe mais, que não consegue fazer mais frente ao espirito de fronteira de Walt Whitman. Mas do herói que mata todos e termina sem saída, pois não há mais ninguém para vencer.

A ausência da máscara dos atores (mas não da fisica da ação) determina a igualdade de expressão entre público e platéia; afinal de contas, estão no mesmo ambiente, unidos pelo mesmo ar que se respira no indisfavoravel e indisfarçado mesmo lugar em que ambos convivem. Esta, num papo informalíssimo e rápido com o diretor, concluímos ter sido foi a característica maior das replicas brasileiras. O publico sempre decidiu a forma final de tudo, mas aqui se finge que não é assim.

\section{O Festival foi ato coletivo de Otium}

O homem não é tão ferido pelo que acontece, $e$ sim por sua opinião sobre o que acontece. Michel de Montaigne.

Nesse espetáculo, os atores vislumbram o público e não escondem que o veem. $\mathrm{O}$ que acontece na parte não iluminada, na mente deles? Oportuna interrogação.

Hoje os famosos estão no lugar da nobreza, a mídia de massa no lugar das bulas e editos, os bancos no lugar das igrejas - ou, vice-versa, das igrejas-banco. As pessoas estão sufocadas pelo consumo, temos instruções precisas sobre a quem odiar. Ninguém tem tempo para nada. $\mathrm{O}$ ócio não existe mais. Somente quem tem poder permite-se ter planos ou projetos. $\mathrm{O}$ restante das populações permanece sempre ameaçado de perder seus parcos meios de sobrevivência, não importa a renda. Perdeu-se o "otium" a favor do "negotium".

No entorno à chaminé da fabrica (construída por Ermelino Matarazzo enquanto negotium para propiciar a riqueza do otium) restaurada como centro cultural, estabeleceu-se uma convivência intelectual que começou por ser acentuada por espetáculos de praça como "Otro", ou o metafisicamente mais convencional "Las Julietas". “Antes", espetáculo que abriu o festival, foi visto por mais de cinco mil pessoas ao ar livre, assumiu o otium geral. Sob aquela chaminé, todas as manifestaçôes, de uma maneira ou de outra, criaram um universo ligado ao publico no momento da performance. Essa construtividade deixaria Tadeusz Kantor muito 
feliz; repetia energicamente que a arte teatral deveria ocorrer diante e com o publico, e não somente para o publico.

No século XVI, a cidadezinha de Sabbionetta, conhecida como "Piccola Atene", foi projetada para ser um negotium, uma fortaleza; mas virou um centro de alta cultura. Ali foram criadas e estabelecidos os padrōes clássicos de representaçôes no teatro, em oposição às paixōes religiosas medievais; o emprego da cenografia da pintada em três dimensões, horizonte alvissareiro do imaginário do espectador.

\section{A chave da escuridão}

O chiaroscuro é uma espécie de perspectiva das cores, através contraste entre luz e sombra na representação de um objeto. A perspectiva exige a perfeita observação da luz em superfícies e das sombras e a transferência desta na tinta. Isso implica que se pode representar sem o emprego de uma linha de contorno. Uma simples alusão técnica ao contraste entre o objeto e o fundo faz todo o trabalho de representação do efeito da luz na realidade e simula volumes. Percebemos assim a tridimensionalidade através das sombras. As ideias mais fortes são representadas através de criações no espaço iluminado da escuridão, em oposição à uma estrutura de objetos iluminados no palco. Estamos no lugar mental da criação e da fruição artística. As pessoas que assistiram aos magníficos "Abracadabra" (de Luiz Paetow) e "Os Cegos" (de Maurice Maetterlink, em holografia) desfrutam disso sem o perceber intelectualmente. Age-se em consciência do que é publico a consciência da escuridão em publico.

O caráter de afirmação de gramáticas deste Festival remeteu-me a uma dialética da nossa atualidade com o criador do verdadeiro teatro renascimental: Leone De Sommi: esse culto judeu dos século XVI, dirigiu e produziu os espetáculos da corte dos Gonzagas em Mantua. O que conhecemos como teatro moderno foi codificado por ele, que estabeleceu do teatro como oficina e o tirou do âmbito da sacra representação. Nada de festa religiosa, mas forma culta repetível de espetáculo.

O impacto disso na sociedade da época equivale à invenção do cinema no século XX. Havia um imenso numero de analfabetas, pessoas sequiosas de aprender tudo o que era linguagem individual, de sair da ótica das corporaçôes. Desenvolveu o que hoje para nos é normalissimo: a relação com si mesmo enquanto personalidade, as grandes aspiraçôes individuais que chamamos de "projeto de vida".

Os "Quattro dialoghi in materia di rappresentazioni sceniche", copia manuscrita de cerca de 1590, propiciaram o nascimento da organização racional dos elementos constitutivos do teatro, da dramaturgia, da linguagem cênica como as conhecemos hoje. Nele estão compiladas as primeiras indicaçôes da mise-enscène e da figura do ator enquanto profissional no teatro ocidental, então obra de cortesãos diletantes para príncipes, prelados ou nascentes burgueses. A interpretação, na maioria das vezes, estava bem mais próxima da realidade da vida. A performance começou a ser mais importante que as palavras do texto (mesmo que ainda não houvesse essa praga da atuação do texto impresso, que leva muitos atores ao diletantismo medieval).

A atividade cênica sistematizada de Leone de Somi criou uma técnica pré-industrial que chamamos de cartesanato de boa qualidade: L'Arte. Era a consciência cênica das impostaçóes vocais, da dicção precisa (no sentido de ser apropriada ao personagem e não à palavra impressa), dos movimentos do corpo, das roupas, da aparência. Obviamente, o realismo era o objetivo: o ciclo da arte como mimese da realidade só iria completar-se no binômio Ibsen Tchekov e seu teatro de arte de Moscou - havia prescrições de cenografias plausíveis, porem sempre em ambientes externos. (Exatamente como os portōes de armazém da cenografia da abertura deste Festival.) A quarta parede era inconcebível, mas não por isso as manifestaçōes deixavam de ser intimistas. Aqui em Rio Preto, 
o intimismo se traduz em palavrōes, que talvez incomodem pessoas, mas todos os empregam. São mero reflexo de estarem incorporados ao linguajar quotidiano.

A palavra é metade de quem a pronuncia, metade de quem a ouve. Michel de Montaigne

\section{A atual realidade do palco propõe uma tensão a mais}

Os limites da representação e da realidade levam a um outro território, quando se trabalha com a direção de atores: a tensão entre aqueles que se consideram profissionais e aqueles que os profissionais consideram amadores. Dentre estes, há os que consideram os "profissionais" um modelo estético a ser seguido e aqueles que simplesmente não consideram o problema. Estes são os não-atores. Gosto muito de trabalhar com eles, preservam a pessoa que são sem se furtar a representar um outro de si.

Muitos "profissionais" procuram falar com a voz empostada pelo que acham que são intençôes estudadas na leitura de mesa. Gritam em alto até mesmo segredos de estado. O teatro lhes conferiria poderes de viver situaçôes extremas impunemente, pensam. Exibem-se generosamente nada mais que péssimos disfarces cênicos de si mesmos, alheios a qualquer característica psicológica ou social daquilo que pensam representar. Não prezam o signo mas o estilo. Tenho calafrios quando desconfio descrever muito maior de profissionais do que gostaria. Alguns, treinados com sinal invertido num improvável Grotowski de oitava mão, têm animais os mais diversos como modelo estético.

Ainda na fabrica, uma extraordinária companhia de jovens chilenos encenou a repressão política no interior das casas que compõe um binômio admirável com o Brecht de praça aberta encenado por Gerogette Fadel. Veem de um estudo serio de Sstanislavski e de teatro de praça. Falam de si, de suas raízes e sabem o que querem contar. Sabem mexer com os limites de si e do outro de si.
O que pode definir os limites e os possíveis contornos desse tipo de tensão teatral pode ser a proximidade ou a distância entre o que artistas expõem deles mesmos ou não. $\mathrm{O}$ que expor e o que não expor? o ator escolhe de um repertorio previamente estudado ou de si mesmo que è o que acha que è o texto que vai representar. Stanislavski me desmentiria. O diretor deles praticamente escreveu o texto através deles. Sugeriu mas não se atreveu entrar muito no jogo efetivo do palco, formalizando o todo num grande exemplo de naturalismo; virou o autor das palavras do espetáculo, uma vez guia$\mathrm{da}$ a linha mestra da dramaturgia e dos ensaios.

$O$ dilema que gostaria de definir é particular: o corpo e a mente do ator são corpo de um ser humano, que naquele momento tem a função de ator. $O$ pianista usa o piano como instrumento. $O$ ator pode somente usar a si, e a sua mente, corpo, sua biografia, suas relaçôes, sua existência presente. Não se trata da mimese da realidade sugerida por Aristóteles. Trata-se daquilo que chamo de credibilidade da representação, da linha de prumo que deve guiar toda e qualquer indicação de direção durante qualquer trabalho. Nesse sentido, endosso o que vi de Giorgio Strehler: a luta por um teatro humano. Não foi por acaso que ele viveu e criou o seu teatro como um serviço público.

Os espetáculos podem viver como um universo crivel através da performance ou podem ser a falência da representação do mesmo em formas estilizadas. Consegue sucesso nessa empreitada somente quem se liberdade suas auto-imposições e fetichismos estéticos para partir do ser humano que se é na direção de um papel crível, sugerido pelo texto ou pelo procedimento criativo empregado.

Daqui para a frente, serei radical com cenografias; quero criar ambientes na verdade e no lugar da representação. Vou dar um jeito, na primeira coisa que fizer, de colocar a velha obsessão dos teatros de anatomia franceses... o corpo morto sobre num pedaço de madeira que seja diferente de um altar, com a aparência desarrumada do teatro ser muito mal- iluminada, de qualquer jeito. A morte será o objeto, como sempre me disse Kantor. 
Nada "ajeitado", "em feito", "profissional"... No palco convencional, hoje, tudo vira um miserável amontoado de lixo, tudo denota falta de recursos de fazer o que se quereria. Simplesmente porque hoje ninguém mais suspende a desconfiança - o velho jogo de Coleridge. "Quero, mas não consigo", dizem na Itália, pejorativamente

No engodo, na estilização, na ideologia vazia trafega um bom dinheiro de subvenção ou de renuncia fiscal, trafega... o Poder. Nesse pântano, profissionais de verdade são bem poucos, se entendidos não como gente obrigada a dar cursos fajutos, fazer bicos, publicidade, mas como gente que ganha a vida com o teatro em que acredita. Nem entendidos como profissionais os que têm o hobby do palco. Há massagistas, advogados, médicos, comerciantes, ninfo-homo-erotomanes que fazem "teatro profissional" nas horas vagas e discriminam artistas sutis na palavra e no gesto (para citar Hamlet). Muitos têm boa qualidades, mas se acabam nessa brincadeira de mediocridade. A maioria morre de fome mas vive de permutas com restaurantes (O que é permuta?), de heranças, de promiscuidades, de sortidas coloraçôes ideológicas.
A presença ator na representação deveria ser enquanto interlocutor direto com a mente de seu publico, antes que este ouça as suas falas. Ele deveria vestir uma roupa como própria antes de vestir um figurino. E isso o público nota mais do que imaginamos. Nós pensamos por linhas estéticas, eles simplesmente veem a coisa. É por isso que é tão fácil de perceber em que determinada década foi rodado tal filme histórico. Por mais perfeccionista e fanática que tenha sido a reconstrução histórica.

Diante disso, a indefectível voz do velho Tadeusz Kantor veio em mente a reafirmar um vaticinio conclusivo:

O espaço da vida é o espaço da arte; ambos confundem-se, compenetram-se e dividem um destino comum; A 'quarta paredé não tem sentido porque a necessidade da obra teatral reside nela própria; o espetáculo acontece não para alguém, mas na presença de alguém; atores não podem fingir uma personagem ou representar um texto; o drama e a vida coincidem na criação de um espetáculo-obra de arte. 